\title{
Study of Marital Satisfaction in Women with a History of Genital Cancers Referred to Selected Centres in Tehran, 2019-2020
}

\author{
Sara Moradi ${ }^{1}$, Leila Nissani Samani², Jamileh Abolghasemi ${ }^{3}$ \\ ${ }^{1,2}$ Department of Midwifery, School of Nursing and Midwifery, Iran University of Medical Sciences, Tehran, \\ Iran. ${ }^{3}$ Department of Biostatistics, School of Health, Iran University of Medical Sciences, Tehran, Iran.
}

\section{ABSTRACT}

\section{BACKGROUND}

We wanted to investigate marital satisfaction in women with gynaecological cancers referred to selected medical centres in Tehran in 2019.

\section{METHODS}

125 women with genital cancer who were referred to selected treatment centres in Tehran were included in the study. Data was collected using ENRICH marital satisfaction demographic questionnaire and analysed using descriptive statistics, SPSS version 22 software.

\section{RESULTS}

The three groups of women with gynaecological cancers did not differed in terms of average marital satisfaction score. Adjusted results based on the covariance analysis test also showed that the difference in the mean score of marital satisfaction in women with genital cancer was not statistically significant at $95 \%$ confidence level. The variance analysis did not significantly differ between the mean score of the components of marital satisfaction and the total marital satisfaction score in women with genital cancer ( $p>0.05$ ). The Pearson correlation coefficient test also did not show a significant relationship between total marital satisfaction and demographic characteristics in women with uterine and ovarian cancers. The results of Pearson's correlation coefficient in the group of women with cervical cancer showed a statistically significant relationship between total marital satisfactions with age at marriage.

\section{CONCLUSIONS}

This study in addition to determining marital satisfaction and its components in women with genital cancers, expands the scope of midwifery science in this field, and can also be used as a basis for further intervention studies.

\section{KEY WORDS}

Uterine Cancer, Ovarian Cancer, Cervical Cancer, Marital Satisfaction
Corresponding Author:

Sara Moradi,

Department of Midwifery,

School of Nursing and Midwifery,

Iran University of Medical Sciences,

Tehran, Iran.

E-mail: saramoradiiums1394@gmail.com

DOI: $10.14260 /$ jemds/2021/46

How to Cite This Article:

Moradi S, Samani LN, Abolghasemi J. Study of marital satisfaction in women with a history of genital cancers referred to selected centres in Tehran, 2019-2020. J Evolution Med Dent Sci 2021;10(04):212216, DOI: $10.14260 / \mathrm{jemds} / 2021 / 46$

Submission 20-09-2020,

Peer Review 14-11-2020,

Acceptance 20-11-2020,

Published 25-01-2021.

Copyright (c) 2021 Sara Moradi et al. This is an open access article distributed under Creative Commons Attribution License [Attribution 4.0 International (CC BY 4.0)] 


\section{BACKGROUND}

Gynaecologic malignancies are one of the most important topics in cancer and social medicine, and account for onethird of all cancers in women. ${ }^{1}$ Reproductive / genital system cancers are stressful events that affect both the physical and psychological aspects of a woman's life. The prevalence of malignant tumours of the female genital tract varies widely around the world. ${ }^{2}$

Among the issues that arise with the development of cancer treatments are aspects of quality of life. Among the various dimensions of quality of life, sexual health and marital satisfaction are of particular interest. Marital satisfaction is an important aspect of public health, especially women's health. In general, the prevalence of marital status problems in the female population is about 40 percent, and in women with gynaecological cancers it is as high as 80 percent. $^{3}$

Today, advanced cancer treatments include a combination of surgery, chemotherapy and radiotherapy. Women who have surgery to remove the uterus or ovaries and then chemotherapy may feel that they have lost their beauty and youth. They may even have unreasonable fears, such as being rejected by their spouse and a feeling of sexual inactivity. 4

Salazar-Molina et al. ${ }^{5}$ (2015), assessed marital satisfaction, physical and mental health during menopause in a statistical population of 142 people at random in Chile. They noted that due to menopause as well as exposure to chemotherapy, physical, mental and psychological changes were significant. Therefore, it is necessary to try to improve the marital satisfaction of people with chronic diseases. ${ }^{6}$

Sexual satisfaction is as a result of the deep dependence between men and women, and if a couple does not show these behaviours, their life is considered superficial and meaningless. ${ }^{7}$ Studies have shown that marital satisfaction and sexual satisfaction are sometimes affected by external factors such as chronic or underlying diseases, contraceptive methods, childbirth, the addition of a child to the family, and a sudden change in economic, occupational and educational status. $^{8}$

In the field of reproductive health, an important issue for women with chronic diseases is reduction of sexual relations, sexual desire, and in some cases sexual thoughts are completely eliminated. ${ }^{9}$ Despite the various effects of the disease and the treatment on the quality of life of the clients, most cancer patients will be able to continue to live an active life with minimal restrictions. Among the factors affecting the quality of life, is the issue of sexual performance and marital satisfaction. The medical staff should be aware of the effects of the disease on people's lives. Also, health care is considered as part of the disease control programs by identifying the effects of the disease on different aspects of life. Thus, appropriate treatment methods can be used, and therapeutic results can be evaluated in a short time surrounded by the effects of cancer, and its treatment can improve the quality of life of cancer patients. ${ }^{10}$

One of the goals of midwifery science is to maintain and promote the health of the family and society. The midwife has an important role in educating, counselling, and administering fertility health not only for women but also for society and the families. Midwife can also play an effective role in this field due to her knowledge and avoid cases of deviation from health and has continuous communication with society. ${ }^{11}$

Since research on various aspects of sexual quality of life, including marital satisfaction of women with cancer in Iran, is scarce, and given that having sexual health and marital satisfaction is very effective in improving the quality of life of a woman with cancer, in the present study, efforts have been made to take effective steps to help solve the problems surrounding patients' quality of life.

\section{METHODS}

The present study was a cross-sectional study to investigate marital satisfaction in women with a history of gynaecologic cancers. The sample size was 125 women with conditions and data was collected from 2019/11/6 to 2020/2/4. Subjects were married Iranian women, at reproductive age, referred to selected medical centres in Tehran, Iran. For this purpose, the necessary permits from the ethics committee of Iran University of Medical Sciences with IR.IUMS number: REC.1398.766 and a letter of introduction for access to research samples were obtained.

\section{Statistical Analysis}

After collection, the data was analysed using SPSS 22. Then, Chi-square test or Pearson correlation coefficient was used to investigate the relationship between marital satisfaction and demographic characteristics. All tests were performed at error levels less than 0.05 .

\section{Study Implementation Method}

The research samples were selected through available sampling among women with genital cancers referred to selected medical centres in Tehran. Entrance criteria for the study included: women aged 15 to 49 years, a history of living together with a spouse for at least the last 6 months, Iranian nationality, lack of polygamy, lack of a history of known mental illness in couples, lack of treatment or counselling in reproductive and sexual context, non-use of psychotropic drugs and drugs affecting sexual activity in couples, lack of addiction and substance abuse in couples, non-occurrence of stressful events unrelated to the current patient in 3 months. Subsequently, informed consent was obtained from the participants and the questionnaires were given to the individuals and after completion, the relevant questionnaires were collected.

\section{Research Tools}

\section{Enrich Marital Satisfaction Questionnaire}

The questions were ranked 1 to 5 using the Likert scale and the content of the questions (i.e., for marital satisfaction or dissatisfaction) was graded in such a way that the total score showed marital satisfaction. The five-choice questionnaire was "I totally agree", "I agree", "I abstained", "I disagree", and "I totally disagree".12 
Permissibility and Reliability of ENRICH Questionnaire

For this, 20 women with genital cancer under chemotherapy were selected. The questionnaire was completed in two stages with 2 weeks interval. Then, using the cluster correlation coefficient (ICC), they were examined and according to the objectives of the study and research conducted in this field ${ }^{13}$ using the formula

$$
n=\frac{Z_{1}^{2}-a /{ }_{2} \sigma^{2}}{d^{2}}
$$

In order to calculate, $95 \%$ confidence level, 6.3 accuracy and 35.8 standard deviation were considered $^{13}$ which resulted in

$$
\frac{1.96^{2} .35 .8^{2}}{6.3^{2}}=124.05 \sim 125
$$

The sample size was 125 subjects.

\section{RESULTS}

The age range of the women in this study was 30 to 41 years, with one type of uterine, ovarian, or cervical cancer. The results showed that the group of women with ovarian cancer with an average age of $39.13 \pm 5.92$ had the highest average

\begin{tabular}{|c|c|c|c|c|c|c|c|}
\hline Factors & $\begin{array}{c}\text { Cancer } \\
\text { Type }\end{array}$ & - Minim & $\begin{array}{l}\text { Maxi } \\
\text { mum }\end{array}$ & Mean & SD. & Result & $\begin{array}{c}\text { Adjusted } \\
\text { Results }\end{array}$ \\
\hline \multirow{3}{*}{$\begin{array}{l}\text { Contractual } \\
\text { response }\end{array}$} & Uterus & 3.00 & 13.00 & 8.4151 & 2.17002 & $\mathrm{~F}=0.281$ & $F=0.324$ \\
\hline & Ovary & 5.00 & 13.00 & 8.6774 & 2.07183 & $P$-value $=$ & $P$-value $=$ \\
\hline & Cervix & 5.00 & 12.00 & 8.7073 & 1.91369 & 0.775 & 0.724 \\
\hline \multirow{3}{*}{$\begin{array}{c}\text { Marital } \\
\text { satisfaction }\end{array}$} & Uterus & 7.00 & 27.00 & 20.5094 & 3.34332 & $F=0.542$ & $F=.321$ \\
\hline & Ovary & 17.00 & 24.00 & 20.0645 & 1.94826 & P-value $=$ & $P$-value $=$ \\
\hline & Cervix & 15.00 & 27.00 & 20.7317 & 2.25859 & 0.583 & 0.726 \\
\hline \multirow{3}{*}{$\begin{array}{l}\text { Personality } \\
\text { issues }\end{array}$} & Uterus & 3.00 & 15.00 & 10.8113 & 2.68941 & $\mathrm{~F}=0.090$ & $\mathrm{~F}=.233$ \\
\hline & Ovary & 7.00 & 15.00 & 11.000 & 2.26569 & $P$-value $=$ & $\mathrm{P}$-value $=$ \\
\hline & Cervix & 6.00 & 15.00 & 10.7561 & 2.42673 & 0.914 & 0.792 \\
\hline \multirow{3}{*}{$\begin{array}{l}\text { Marital } \\
\text { relationship }\end{array}$} & Uterus & 5.00 & 15.00 & 10.3396 & 2.74523 & $F=0.556$ & $\mathrm{~F}=.411$ \\
\hline & Ovary & 7.00 & 15.00 & 10.8265 & 2.38634 & P-value $=$ & $\mathrm{P}$-value $=$ \\
\hline & Cervix & 6.00 & 15.00 & 10.1951 & 2.28276 & 0.575 & 0.664 \\
\hline \multirow{3}{*}{$\begin{array}{l}\text { Conflict } \\
\text { resolution }\end{array}$} & Uterus & 5.00 & 20.00 & 14.6038 & 3.18856 & $F=0.583$ & $\mathrm{~F}=.761$ \\
\hline & Ovary & 9.00 & 20.00 & 15.2903 & 2.50591 & $P$-value $=$ & $P$-value $=$ \\
\hline & Cervix & 9.00 & 21.00 & 14.9268 & 2.55333 & 0.560 & 0.469 \\
\hline \multirow{3}{*}{$\begin{array}{c}\text { Financial } \\
\text { Management }\end{array}$} & Uterus & 3.00 & 15.00 & 10.3774 & 2.24659 & $F=1.58$ & $F=1.27$ \\
\hline & Ovary & 8.00 & 15.00 & 11.1613 & 1.80918 & $\mathrm{P}$-value $=$ & $\mathrm{P}$-value $=$ \\
\hline & Cervix & 6.00 & 15.00 & 10.9024 & 1.99756 & 0.208 & 0.282 \\
\hline \multirow{3}{*}{$\begin{array}{c}\text { Leisure } \\
\text { activities }\end{array}$} & Uterus & 4.00 & 20.00 & 13.0943 & 2.74748 & $\mathrm{~F}=1.82$ & $\mathrm{~F}=1.18$ \\
\hline & Ovary & 11.00 & 20.00 & 14.0968 & 1.79545 & $\mathrm{P}$-value $=$ & $\mathrm{P}$-value $=$ \\
\hline & Cervix & 9.00 & 16.00 & 13.4146 & 2.07335 & 0.166 & 0.309 \\
\hline \multirow{3}{*}{$\begin{array}{l}\text { sexual } \\
\text { relations }\end{array}$} & Uterus & 4.00 & 19.00 & 12.3208 & 2.70166 & $F=0.728$ & $\mathrm{~F}=.553$ \\
\hline & Ovary & 9.00 & 20.00 & 12.806 & 1.93940 & $P$-value $=$ & $P$-value $=$ \\
\hline & Cervix & 7.00 & 16.00 & 12.1463 & 2.13964 & 0.428 & 0.576 \\
\hline \multirow{3}{*}{$\begin{array}{l}\text { Marriage and } \\
\text { children }\end{array}$} & Uterus & 4.00 & 16.00 & 10.6038 & 2.27308 & $\mathrm{~F}=0.472$ & $\mathrm{~F}=0.720$ \\
\hline & Ovary & 8.00 & 20.00 & 11.0323 & 2.22836 & $P$-value $=$ & $\mathrm{P}$-value $=$ \\
\hline & Cervix & 6.00 & 16.00 & 10.5610 & 2.18001 & 0.625 & 0.489 \\
\hline \multirow{3}{*}{$\begin{array}{l}\text { Relatives and } \\
\text { friends }\end{array}$} & Uterus & 4.00 & 20.00 & 11.5660 & 2.3657 & $F=0.187$ & $\mathrm{~F}=.159$ \\
\hline & Ovary & 8.00 & 20.00 & 11.6452 & 2.45694 & $P$-value $=$ & $\mathrm{P}$-value $=$ \\
\hline & Cervix & 8.00 & 15.00 & 11.3415 & 1.90538 & 0.829 & 0.853 \\
\hline \multirow{3}{*}{$\begin{array}{l}\text { Men and } \\
\text { women } \\
\text { equality }\end{array}$} & Uterus & 2.00 & 10.00 & 5.9057 & 1.53503 & $\mathrm{~F}=0.231$ & $\mathrm{~F}=.580$ \\
\hline & Ovary & 3.00 & 10.00 & 6.1290 & 1.68804 & $P$-value $=$ & $P$-value $=$ \\
\hline & Cervix & 4.00 & 8.00 & 5.9756 & 1.12889 & 0.794 & 0.562 \\
\hline \multirow{3}{*}{$\begin{array}{l}\text { Ideological } \\
\text { orientation }\end{array}$} & Uterus & 6.00 & 16.00 & 10.773 & 2.47791 & $\mathrm{~F}=1.43$ & $\mathrm{~F}=1.48$ \\
\hline & Ovary & 4.00 & 18.00 & 10.225 & 3.32375 & $\mathrm{P}$-value $=$ & P-value $=$ \\
\hline & Cervix & 6.00 & 16.00 & 11.341 & 2.69824 & 0.241 & 0.232 \\
\hline \multirow{3}{*}{$\begin{array}{l}\text { Total marital } \\
\text { satisfaction }\end{array}$} & Uterus & 53.00 & 166.00 & 139.320 & 18.60601 & $\mathrm{~F}=0.550$ & $\mathrm{~F}=.815$ \\
\hline & Ovary & 121.00 & 195.00 & 142.930 & 13.65268 & $\mathrm{P}$-value $=$ & $\mathrm{P}$-value $=$ \\
\hline & Cervix & 114.00 & 166.00 & 141.000 & 11.31592 & 0.578 & 0.445 \\
\hline
\end{tabular}
age among the studied units.

The results of the analysis of variance test showed that the difference between the mean score of marital satisfaction and total marital satisfaction score in women with genital cancers was not statistically significant at $95 \%$ confidence level $(p>0.05)$. The results adjusted based on the covariance analysis test also showed that the difference between the mean score of marital satisfaction and total marital satisfaction score in women with genital cancers was not

\begin{tabular}{|c|c|c|c|c|c|c|c|}
\hline$\frac{0}{\frac{0}{0}}$ & 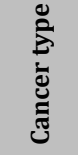 & 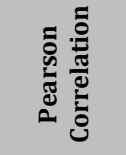 & $\stackrel{\square}{\leftarrow}$ & 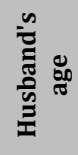 & 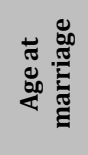 & 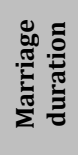 & 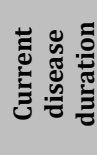 \\
\hline \multirow{4}{*}{$\begin{array}{c}\text { Total } \\
\text { marital } \\
\text { satisfaction }\end{array}$} & Uterus & $\begin{array}{c}\text { Correlation } \\
\text { P-value }\end{array}$ & $\begin{array}{l}0.148 \\
0.292\end{array}$ & $\begin{array}{l}0.028 \\
0.842\end{array}$ & $\begin{array}{c}-0.091 \\
0.515\end{array}$ & $\begin{array}{l}0.208 \\
0.135\end{array}$ & $\begin{array}{l}0.223 \\
0.109\end{array}$ \\
\hline & Ovary & Correlation & - 0.114 & -0.106 & 0.176 & $\begin{array}{c}-0.074 \\
\end{array}$ & $\begin{array}{c}-0.186 \\
0.317\end{array}$ \\
\hline & \multirow{2}{*}{ cervix } & Correlation & -0.291 & -0.232 & $-0.374^{*}$ & -0.109 & -0.006 \\
\hline & & P-value & 0.065 & 0.144 & 0.016 & 0.497 & 0.972 \\
\hline
\end{tabular}
statistically significant $(\mathrm{p}>0.05)$.

Demographic Characteristics in Women with Gynaecologic Cancers

In women with uterine and ovarian cancers, the results of the Pearson correlation coefficient test did not indicate a significant relationship between total marital satisfaction and demographic characteristics. But in the group of women with cervical cancer, a statistically significant relationship was observed between total marital satisfactions with age at marriage $(\mathrm{p}<0.05)$.

\section{DISCUSSION}

Cancer is the second leading cause of death in the United States and many other countries.14 One of the important issues in the study of patients with chronic diseases, including cancer, is to pay attention to the quality of life of patients. Considering the factors related to the quality of life of cancer patients is an important point in evaluating the effectiveness of treatment and the course of the disease in these patients. The psychological effects of cancer diagnosis and the physical effects of its treatment are associated with many of the side effects that adversely affect a person's quality of life. ${ }^{15}$ According to the mentioned information, in the present study, an attempt has been made to evaluate the marital satisfaction of women with genital cancers referred to selected medical centres in Tehran in 2019.

The age range of the subjects was 30 to 41 years, and they had one type of uterine, ovarian, and cervical cancer. The results of the analysis of variance test showed that the group of women with ovarian cancer with a mean age of $39.13 \pm$ 5.92 had the highest average age among the studied units. The age of the spouses of the three groups did not show significant difference $(p>0.05)$. The results showed that the age of marriage of the studied units did not have significant difference $(p=0.111)$. Three groups of women with genital cancer differed in terms of the average duration of marriage ( $p=0.005$ ), and the group with ovarian malignancy had the highest average duration of marriage among the three groups. The results also showed that the three groups of women with genital cancer did not differ in the average length of the disease ( $p=0.285$ ).

In the study of Addis et al. ${ }^{16}$ (2006), women's sexual satisfaction decreased with age; or in the study of Hendrickx et al. ${ }^{17}$ (2015), with increasing age, women's motivation to have sex with their spouses decreased. In some other studies, 
the age gap between spouses.18,19 and the length of marriage. ${ }^{20,21}$ were also among the most important factors that affect women's sexual dissatisfaction was mentioned.

The results of the analysis of variance test showed that the difference between the mean score of marital satisfaction and total marital satisfaction score in women with genital cancer was not statistically significant at $95 \%$ confidence level ( $p>0$ / 05). This means that the three groups of women with genital cancer do not differ in terms of the average score of the marital satisfaction components and the overall marital satisfaction score $(\mathrm{p}=0.058)$. The results adjusted based on the covariance analysis test also showed that the difference between the mean score of marital satisfaction and total marital satisfaction score in women with genital cancer is not statistically significant at $95 \%$ confidence level. The mean on total marital satisfaction in the uterine cancer group was 139 / $32 \pm 18$ / 60, in the ovarian cancer group it was $142.93 \pm$ 13.65 , and in the cervical cancer group it was $141 \pm 11.31$.

Esfandiari Dolabi et al. (2015) did not show a significant difference between the mean score of variable marital satisfaction in the group of female cancer patients with healthy women.22 Also, Naghipour et al. (2013) in a study evaluated sexual satisfaction, body image and quality of life among three groups of women with breast cancer in two groups of mastectomy and breast surgery and healthy women. ${ }^{23}$ They found that there was no significant difference between the three groups of women studied in the variables of sexual satisfaction and physical perception.

In general, a comparison of the results of the present study with the above studies shows that there is no significant relationship between the components related to sexual satisfaction in patients with female cancers. Therefore, more variables need to be considered in order to obtain more accurate results.

The results of the present study on the social dimension of patients' quality of life, which according to Zamanzadeh et al. ${ }^{24}$ (2007) include two subsets of relationship with spouse or close people and relationship with relatives, showed that there was no significant relationship between components such as marital satisfaction, personality issues, marital relationship, conflict resolution, leisure activities, sex, marriage and children and friends and relatives with the type of cancer among patients ( $p>0.05$ ). In the study of Heidarzadeh et al. ${ }^{25}$ (2006), the social dimension of quality of life was reported in $52 \%$ of patients. Eghtedar et al. ${ }^{26}$ (2010) has also reported the social dimension of breast cancer patients. However, Zeighami Mohammadi and Ghaffari 27 (2008) have reported the most common form of sexual problem in women with breast cancer is a decrease in the desire to have sex and dyspareunia.

Badakhsh et al.28 (2009) stated that following hysterectomy, the number of people without sexual satisfaction or with poor satisfaction increased significantly and the number of people with desirable and excellent satisfaction decreased. The results of the present study were not consistent with the results of Badakhsh et al. ${ }^{28}$ (2009). In the present study, couple sexual relations with a coefficient of $0.428(\mathrm{p}=0.428)$ were statistically less than the total marital satisfaction $(\mathrm{p}=0.058)$, but this amount was not significant. However, by conducting psychological interviews and appropriate psychological support, it is possible to help improve the condition of patients with various types of genital cancer and, as a result, overall marital satisfaction.

According to Reese et al. ${ }^{14}$ (2019), restoring sexual habits after cancer can significantly affect the quality of life of patients. Falk et al. (2020) stated that the incidence of cancer, especially genital cancers in infected women, could have broad implications for factors related to sexual function and sexual satisfaction. ${ }^{29}$ These cancers significantly reduce sexual satisfaction in these people. The results of the present study on sexual satisfaction (marital satisfaction) showed a mismatch with the expression of the Falk et al. ${ }^{29}$ (2020) and not significant in this feature. Various factors such as cultural and social issues, especially how people answer the relevant questions is involved.

By determining marital satisfaction and its components in women with genital cancers, in addition to expanding the scope of midwifery science in this field, this study can be used as a basis for further intervention studies. Doing such research can play a role in improving the quality of life. In addition, basic descriptive studies on genital cancers with a health approach can be a source of science and strategies for improving the quality of life in the health sciences, sociology, and women's and family psychology.

Marital satisfaction among women with various types of genital cancers is one of the most important and influential factors in married life. As a result of many problems and disputes between couples and eventually divorces, sexual dissatisfaction can cause irreparable damage to the quality of marital relations and the foundation of the family. In sexual satisfaction, couples can have equally positive effects on individual and social life. According to the results of this study, the average score of total sexual satisfaction in women with one of the three types, cancer of the uterus, ovaries and cervix was obtained at a high level, which is important in its kind.

It is suggested that the results of this study be made available to policymakers and population and family health planners, such as women counsellors and research and health vice chancellors of medical universities, so that future research can identify the most important factors influencing these two family and social issues. Universities (family and population health units) that provide health services to this portion of the population and the counselling and (mental health) unit of this vice chancellor regarding the most important and most practical educational and noneducational interventions, plan and take the necessary measures.

\section{CONCLUSIONS}

This study in addition to determining marital satisfaction and its components in women with genital cancers, expands the scope of midwifery science in this field, and can also be used as a basis for further intervention studies.

Data sharing statement provided by the authors is available with the full text of this article at jemds.com.

Financial or other competing interests: None.

Disclosure forms provided by the authors are available with the full text of this article at jemds.com. 


\section{REFERENCES}

[1] Audette C, Waterman J. The sexual health of women after gynecologic malignancy. J Midwifery Womens Health 2010;55(4):357-62.

[2] Hajian A, Souradeep T. Measuring the statistical isotropy of the cosmic microwave background anisotropy. Astrophys J Lett 2003;597(1):L5.

[3] Jemal A, Siegel R, Xu J, et al. Cancer Statistics, 2010. CA Cancer J Clin 2010;60(5):277-300.

[4] Du Z, Qu H. The relationship between ovarian function and ovarian limited dose in radiotherapy postoperation of ovarian transposition in young patients with cervical cancer. Cancer Med 2017;6(3):508-15.

[5] Salazar-Molina A, Klijn TP, Delgado JB. Sexual satisfaction in couples in the male and female climacteric stage. Cad Saude Publica 2015;31(2):311-20.

[6] McRee AL, Haydon AA, Halpern CT. Reproductive health of young adults with physical disabilities in the US. Prev Med 2010;51(6):502-4.

[7] Slosarz WJ. Relations between lifestyle and factors affecting sexual life. Sexual and Relationship Therapy 2000;15(4):367-80.

[8] Yousefzadeh S, Golmakani N, Nameni F. The comparison of sex education with and without religious thoughts in sexual function of married women. Journal of Midwifery and Reproductive Health 2017;5(2):904-10.

[9] Abe A, Kuwahara A, Iwasa T, et al. A survey on fertility management in young women of reproductive age treated with chemotherapy. Int J Clin Oncol 2016;21(6):1183-90.

[10] Pai RR, Ongole R. Nurses' knowledge and education about oral care of cancer patients undergoing chemotherapy and radiation therapy. Indian J Palliat Care 2015;21(2):225-30.

[11] Reis N, Beji NK, Coskun A. Quality of life and sexual functioning in gynecological cancer patients: results from quantitative and qualitative data. Eur J Oncol Nurs 2010;14(2):137-46.

[12] Fowers BJ, Olson DH. Enrich marital inventory: a discriminant validity and cross-validation assessment. J Marital Fam Ther 1989;15(1):65-79.

[13] Azizi S, Rahmani A, Ghaderi B. Marital satisfaction among patients with cancer. Nursing and Midwifery Journal 2010;5(17).

[14] Reese JB, Sorice K, Lepore SJ, et al. Patient-clinician communication about sexual health in breast cancer: a mixed-methods analysis of clinic dialogue. Patient Educ Couns 2019;102(3):436-42.

[15] Mayer S, Iborra S, Grimm D, et al. Sexual activity and quality of life in patients after treatment for breast and ovarian cancer. Arch Gynecol Obstet 2019;299(1):191201.
[16] Addis IB, Van Den Eeden SK, Wassel-Fyr CL, et al. Sexual activity and function in middle-aged and older women. Obstet Gynecol 2006;107(4):755-64.

[17] Hendrickx L, Gijs L, Enzlin P. Age-related prevalence rates of sexual difficulties, sexual dysfunctions and sexual distress in heterosexual women: results from an online survey in flanders. J Sex Med 2015;12(2):424-35.

[18] Shahhosseini Z, Gardeshi ZH, Pourasghar M, et al. A review of affecting factors on sexual satisfaction in women. Mater Sociomed 2014;26(6):378-81.

[19] Ziherl S, Masten R. Differences in predictors of sexual satisfaction and in sexual satisfaction between female and male university students in Slovenia. Psychiatr Danub 2010;22(3):425-9.

[20] Tehrani FR, Farahmand M, Mehrabi Y, et al. Prevalence of female sexual dysfunction and its correlated factors: a population based study. Payesh (Health Monitor) 2012;11(6):869-75.

[21] Yoo H, Bartle-Haring S, Day RD, Gangamma R. Couple communication, emotional and sexual intimacy and relationship satisfaction. J Sex Marital Ther 2014;40(4):275-93.

[22] Dolabi ZE, Joulaei A, Azad MA. Comparison of marital satisfaction and general health among breast cancer patients with breast evacuation, breast keeping and cancer free women in Tehran. Iranian Journal of Rehabilitation Research in Nursing 2015;1(4):39-48.

[23] Naghipoor L, Zarea BAM, Taghiloo S, et al. Sexual satisfaction, body image and quality of life: a comparison of unaffected women and women with breast cancer in two groups: Mastectomy surgery and surgery-preserving breast. Womens Studies 2013;10(4):41-62.

[24] Zamanzadeh V, Heidarzadeh M, Oshvandi K, et al. Relationship between quality of life and social support in hemodialysis patients in Imam Khomeini and Sina educational hospitals of Tabriz University of medical sciences. Medical Journal of Tabriz University of Medical Sciences 2007;29(1):49-54.

[25] Heidarzadeh M, Zamanzadeh V, Lakdizejee S. Quality of life and it's dimensions in hemodialysis patients. J Tabriz Nurs Midwifery Fac 2006;4:52-9.

[26] Eghtedar S, Moghadasian S, Ebrahimi H, et al. Evaluation of nursing supportive care in breast cancer. Iranian Quarterly Journal of Breast Diseas 2009;2(3-4):55-60.

[27] Zeighami Mohammadi S, Ghaffari F. Sexual dysfunction and its correlation with quality of life among women affected with cancer. The Iranian Journal of Obstetrics, Gynecology and Infertility 2009;12(2):39-46.

[28] Badakhsh M, Taftachi F, Mehrabi F, et al. The effect of hysterectomy in securing sexual desire and satisfaction. Iranian Journal of Surgery 2009;17(1).

[29] Falk SJ, Dizon DS. Sexual health issues in cancer survivors. Semin Oncol Nurs 2020;36(1):150981. 